\title{
Entrelaçamentos entre histórias de vida de mulheres aprisionadas: dar a palavra, aguçar a escuta ${ }^{1}$
}

\author{
Junielen Veleda Gomes ${ }^{2}$ \\ Jaqueline Lidorio de Mattia ${ }^{3}$ \\ Viviane Castro Camozzato ${ }^{4}$
}

\begin{abstract}
Resumo
O presente artigo parte do seguinte questionamento: Como mulheres aprisionadas em Bagé contam suas histórias de vida e, ao mesmo tempo, a partir de que condições estas mesmas histórias se entrelaçam? O objetivo principal é dar voz a essas mulheres privadas de liberdade, para problematizar as condições sociais e culturais que se incorporam às histórias de vida das apenadas. O caminho metodológico partiu de autobiografias, cujas escritas foram efetuadas em cadernos pelas próprias detentas e posteriormente lidas e analisadas. Houve a intenção de dar voz a elas através de escritas individuais, tendo em vista que a escrita é uma das vias que possibilita a reflexão sobre suas próprias vidas. A pesquisa traz desde narrativas das vidas pré-cárcere até uma análise de suas vidas, enumerando alguns fatores quanto à ineficácia e ressocialização da prisão, bem como a ausência de uma educação que qualifique essas mulheres. As marcas de gênero são algo presente no decorrer de toda a discussão, uma vez que as mulheres parecem submetidas ao domínio do "mundo masculino", traduzido nas relações de violência estabelecidas por parte dos homens, pelo abandono afetivo, financeiro e, ainda, devido ao fato de as mulheres aprisionadas estarem, em sua maioria, na prisão, por terem sido levadas a traficar a partir de figuras masculinas.
\end{abstract}

Palavras-Chave: Prisão; Gênero; Mulheres; Histórias de vida; Educação.

\section{Introdução}

Este artigo originou-se de uma pesquisa sobre histórias de vida de mulheres encarceradas, realizada na cidade de Bagé, Rio Grande do Sul. O referido estudo objetivou dar voz a essas mulheres para que possam ser visualizadas não apenas a partir do termo "marginais" - o qual é redutor por não permitir considerarmos suas trajetórias de vida, suas condições e alternativas, em suma, as condições de produção dessas mesmas vidas -, mas sim como pessoas com determinadas marcas constitutivas e, ao mesmo tempo, com possibilidades

\footnotetext{
${ }^{1}$ Agradecemos aos pareceristas ad hoc que, cuidadosamente, teceram sugestões e apontamentos que ajudaram a qualificar o trabalho.

${ }^{2}$ Especialista em Docência no Ensino Religioso pela Universidade Estadual do Rio Grande do Sul (UERGS). Bagé, Rio Grande do Sul; E-mail: junielenv@gmail.com

${ }^{3}$ Doutoranda no Programa de Bioenergia da Faculdade de Ciências e Tecnologia na Universidade Nova de Lisboa. Professora assistente da Universidade Estadual do Rio Grande do Sul (UERGS). Novo Hamburgo, Rio Grande do Sul; E-mail: jaquelinedemattia@gmail.com
}

${ }^{4}$ Doutora em Educação pela Universidade Federal do Rio Grande do Sul (UFRGS). Professora adjunta da Universidade Estadual do Rio Grande do Sul (UERGS). Bagé, Rio Grande do Sul; E-mail: vicamozzato@gmail.com 
RELACult - Revista Latino-Americana de Estudos em Cultura e Sociedade

Revista Latinoamericana de Estudios en Cultura y Sociedad | Revue Latino-américaine d'Études sur la culture et la société |

de assumirem novos lugares na sociedade sem levar consigo os estigmas da prisão. Para isso, optamos por analisar as histórias de vida dessas mulheres e os seus entrelaçamentos.

Para o presente artigo focaremos em duas histórias de vida, a fim de que possamos, de fato, escutá-las. Considerando isso, indicamos os objetivos a seguir: a) identificar os fatos e acontecimentos marcantes na vida dessas mulheres; b) problematizar as condições sociais e culturais que se incorporam às histórias de vida das apenadas; c) analisar os possíveis entrelaçamentos entre as histórias e as suas marcas de gênero.

Nosso intuito foi por entender as suas histórias de vida narradas do modo como escolhessem, dando valor às suas palavras e à liberdade de expressão. Nesse sentido, Abrahão (2003, p. 13) comenta que "essa unicidade do tempo narrado pode ser detectada em diversas narrativas autobiográficas", o que indica as "reconstruções e ressignificações que o sujeito que rememora faz sobre a própria trajetória." Ainda na linha de Abrahão (2003), fizemos uso do método de pesquisa autobiográfica, analisando as narrativas das apenadas escritas em cadernos individuais, que foram distribuídos no primeiro e no segundo encontro e recolhidos à medida que as participantes se sentiram à vontade, não ultrapassando cinco semanas.

Desse modo, dados os objetivos deste artigo, priorizamos um tipo de escrita que exige uma constituição de si ao escrever, que, conforme análise de Foucault (2004), a partir dos gregos, comportava duas formas de escrita, quais sejam: os hypómnemata ${ }^{5}$ as correspondências. Considerando isso, cremos que a escrita de si por intermédio dos cadernos incitava a um reencontro constante de cada uma consigo e com as singularidades de suas trajetórias de vida. A nosso ver, o retorno a si, realizado durante a escrita, permitia que cada uma das mulheres fizesse uma "dobra" constitutiva sobre si, permitindo o reconhecimento de dois movimentos éticos basilares: um percurso ao encontro das intensidades de suas vidas e às possibilidades de se reencontrarem e transformarem a si.

A partir disso, cada uma revisitou momentos de suas histórias a partir da escrita de si, experimentando deslocamentos em relações ao vivido no passado e no presente. Uma reativação, em suma, a um estado de atenção e cuidado sobre si mesmas. O que indica, sobretudo, uma abertura potente sobre o mundo e sobre si. Almejamos, com isso, que as apenadas pudessem, ao escrever, realizar uma reflexão e a constituição de si. Por esse motivo foram incitadas a escreverem livremente nos cadernos disponibilizados. Outra justificativa se

\footnotetext{
${ }^{5}$ Refere-se a livros de notas muito utilizados pelos gregos para serem registradas lembranças. Sendo assim, as hypómnemata são um tipo de registro que proporcionam, através da escrita, a constituição ética e estética de si.
} 
RELACult - Revista Latino-Americana de Estudos em Cultura e Sociedade

Revista Latinoamericana de Estudios en Cultura y Sociedad | Revue Latino-américaine d'Études sur la culture et la société |

deve ao fato de que nessas escritas temos a oportunidade de conhecer um pouco da realidade social e multifacetária das detentas, não apenas por meio de estatísticas, mas compreendendo o fenômeno em estudo através de categorização feita a partir de acontecimentos que se aproximam/assemelham entre as histórias.

Trabalhamos, assim, com histórias de vida de relatos cruzados. O que, conforme orienta Abrahão (2003), viabiliza a compreensão não apenas individual, posto que permite, além disso, detectarmos as contingências mais amplas que têm produzido e tornado possíveis as histórias de vida das mulheres aprisionadas em Bagé, Rio Grande do Sul.

\section{Uma breve contextualização sobre mulheres na prisão em Bagé}

O espaço existente é ocupado por 16 apenadas do regime fechado, com as delimitações de espaços fixadas por beliches construídos de concreto, onde os espaços são ocupados por grau de afinidade e uma hierarquia de antiguidade. Segundo as apenadas, quem possui a "sorte" de ocupar a parte de baixo do beliche possui vantagem, pois pode montar suas “jegas" (jargão utilizado pelas detentas para nomear o fechamento, geralmente com cobertores, do espaço entre os beliches, deixando-o com aspecto de barracas improvisadas). $\mathrm{O}$ que, de certa forma, lhes assegura um pouco de privacidade e a possibilidade de momentos de visitas íntimas com os seus companheiros, uma vez que no presídio inexiste local separado destinado para essa finalidade. No entanto, visitas tanto de companheiros ou de familiares é algo praticamente inexistente para parte considerável das detentas. Elas são "esquecidas" no cárcere, sendo as visitas de familiares escassas.

Para passar o tempo, as detentas optam por jogar baralhos, ler revistas, jornais e até fazer ginástica com aulas ministradas por uma das reclusas. Outras participam, uma vez por semana, de cultos evangélicos ou católicos ministrados por missionários devidamente autorizados.

Há, inclusive, uma escola funcionando no presídio. A escola tem como responsável uma professora com larga experiência em educação prisional, além de três professores que colaboram ministrando aulas à massa carcerária interessada. Entretanto, o número de alunas está aquém do esperado, pois apenas três detentas, não participantes da pesquisa, frequentam assiduamente as aulas. Diferentemente dos homens, aliás, cujo número de alunos é bem maior: cerca de 90 alunos. Porém, essa é uma diferença aceitável devido o contingente carcerário masculino ser de 256 pessoas.

A educação deve ser entendida como funcionando para além de uma sala de aula. Por esse motivo, cremos que é necessário que as atividades sejam adequadas ao ambiente 
RELACult - Revista Latino-Americana de Estudos em Cultura e Sociedade

Revista Latinoamericana de Estudios en Cultura y Sociedad | Revue Latino-américaine d'Études sur la culture et la société |

carcerário para que possam provocar transformações significativas nas vidas dessas mulheres e no convívio social com as demais apenadas, de modo que as aulas serviriam não apenas para "mantê-las ocupadas". Onofre (2011, p. 288) corrobora estas palavras ao assinalar que a escola deve

\begin{abstract}
ser apontada como local de comunicação, de interações pessoais, onde o aprisionado pode se mostrar sem máscaras, afigura-se, portanto, como oportunidade de socialização, na medida em que oferece ao aluno outras possibilidades referenciais de construção de sua identidade e de resgate da cidadania perdida.
\end{abstract}

Entretanto, não nos referimos apenas à educação escolar, pois a educação não formal, também compõe os indivíduos, tendo em vista que os processos educativos ocorrem tanto dentro quanto fora dos espaços formais da instituição escolar. Por exemplo, no caso das apenadas no estudo mais geral, temos uma cozinheira profissional e uma artesã que poderiam, através dessas atividades, socializar seus conhecimentos às demais - o que, pensadas a partir de um conjunto efetivo de ações que procurassem agir para a transformação da vida dessas mulheres, proporcionaria um pós-cárcere com mais escolhas possíveis, talvez. A nosso ver, fica visível o quanto a ressocialização das mulheres aprisionadas seria favorecida a partir do entrelaçamento incessante entre a educação formal e a educação não formal, visto que são complementares.

O poder público, através da Lei de execução Penal nº 7.210, de 11 de julho de 1984, visa proporcionar condições para a harmônica integração social do condenado. O Art. 19 prevê que o ensino profissional será ministrado em nível de iniciação ou de aperfeiçoamento técnico e que a mulher condenada terá ensino profissional adequado à sua condição. Porém, nem sempre o Estado consegue pôr em prática o necessário para cumprir com eficácia o que está previsto. Isso é possível de ser percebido através da falta de ocupação e qualificação das detentas, que passam a maior parte do cumprimento de sua sentença de forma ociosa. Não possuem sequer liga laboral administrativa, pelo fato de os trabalhos disponíveis possuírem contato com a massa carcerária masculina, o que inviabiliza a aplicação das mulheres nas funções.

Nesse sentido, vale ressaltar o que aponta Chies e Varela (2007, p. 10), ao refletirem sobre o trabalho oferecido para as mulheres aprisionadas:

[...] As manifestações, entretanto, não tendem a incluir significativas perspectivas de acesso ao mundo do trabalho formal. O artesanato, a costura, a faxina, a cozinha, sugerem mais uma "alternativa" de trabalho autônomo e precário do que uma efetiva possibilidade de emprego.

Diante dessa realidade, as mulheres participantes da pesquisa que gerou este artigo queixam-se da falta de oportunidades, o que seria uma forma de apoucar o tempo na prisão 
RELACult - Revista Latino-Americana de Estudos em Cultura e Sociedade

Revista Latinoamericana de Estudios en Cultura y Sociedad | Revue Latino-américaine d'Études sur la culture et la société |

através da remição do tempo - dedução de um dia da pena a cada três dias trabalhados - e, aliado a isso, fornecer ocupação, tirando-as da ociosidade.

Importante registrar que o perfil das apenadas é composto, em sua maioria, por mulheres jovens, negras ou pardas, advindas de classe social vulnerável. Elas cumprem pena por tráfico de drogas e entorpecentes, são reincidentes do sistema prisional e não possuem profissão específica. Quanto à formação educacional, possuem ensino fundamental incompleto, têm parentes de primeiro grau também reclusos, geralmente filhos ou companheiros/maridos.

A partir de conversas com as detentas, pudemos perceber que são mulheres nutridas do desejo de alcançar a liberdade e desfrutá-la junto de suas famílias, principalmente ao lado de seus filhos, os quais, por ordem judicial, quando não há parentes interessados e que preencham os requisitos para assumir sua tutela, são postos em instituições de acolhimento ou encaminhados para adoção.

\section{Narrativas de vidas: marcas constituidoras}

Apresentamos, neste momento, algumas das principais histórias e marcas presentes nas escritas das duas detentas em destaque neste artigo. O objetivo, com isso, é agir eticamente ao dar a palavra a essas mulheres da forma mais direta possível.

\section{C.22 ${ }^{6}$ - ninguém me via ninguem me conhecia}

Primogênita de família de origem pobre, C.22 possui oito irmãos. Não teve a presença paterna em sua vida, e o padrasto que exercia essa função a submeteu desde muito cedo à violência doméstica, como ela mesma salienta: "eu convivi desde pequena com a minha mãe sofrendo agreções de meu padrasto e nós sofríamos também agresão ${ }^{7} . "$

Aos 12 anos de idade, presenciou uma conturbada ruptura do relacionamento de sua mãe com o padrasto, cujo sofrimento facilitou o envolvimento da genitora com drogas, chegando inclusive a prostituir-se na própria residência e a entregar-se totalmente aos vícios, quando, então, escorraçava os filhos. Diante desse contexto, as autoridades destituíram a mãe de C.22 da guarda dos filhos. Com a família em meio a uma desorganização constante, tendo ficado alguns dos irmãos sob a responsabilidade do padrasto, outros com o avô ou parentes

\footnotetext{
${ }^{6}$ Optamos por preservar o nome das pesquisandas fazendo uso da letra inicial e da idade. Esperamos, assim, preservar suas identidades a fim de evitar constrangimentos após a saída da instituição carcerária.

${ }^{7}$ Nos excertos disponibilizados neste artigo, a escrita das mulheres aparece sem correções de nossa parte. Tal opção é realizada a fim de manter uma possível fidelidade às possíveis inscrições de gênero, geração e classe social dos sujeitos.
} 
RELACult - Revista Latino-Americana de Estudos em Cultura e Sociedade

Revista Latinoamericana de Estudios en Cultura y Sociedad | Revue Latino-américaine d'Études sur la culture et la société |

próximos, com 15 anos C.22 foi encaminhada para uma casa acolhedora: "fui para o lar de meninas porque minha mãe fraca pelo vicio de bebida e meu pai Fabiano estava preso, ele sempre teve desde que nasci..."

No abrigo para menores, C.22 passou a fugir e a frequentar boates. Nesse lugar conheceu um homem trinta anos mais velho e com este teve sua primeira filha. Quando decidiu não mais viver o relacionamento, que julgava ser conturbado, retornou ao lar de meninas e perdeu a guarda da filha. Isso porque, quando a menina nasceu, ela era uma mãe menor de idade e, por não ter responsáveis, o registro de nascimento do bebê foi feito somente em nome do pai da criança, que por ter melhores condições financeiras obteve o direito da guarda.

Diante desta situação, a adolescente fugiu do lar - desta vez para não voltar mais. Começou a frequentar a noite, fumar cigarros e beber: "Desisti de ter minha filha novamente nos braços novamente [...] sofri muito com a perca da minha filha com a separação dos meus irmãos e com a destruição da vida da minha mãe..." Numa dessas festas noturnas C.22 adentrou no mundo obscuro das drogas: "eu conheci uma guria que fumava maconha então fumei para esquecer, conheci a cocaína usei para aliviar meu sofrimento, bebia cada vez mais todas as noites..."

$\mathrm{Na}$ ânsia de mudar sua vida, aceitou um convite de uma suposta amiga para ir trabalhar em uma creche na cidade de Porto Alegre. Arriscou-se de carona até o destino. Ao chegar percebeu que foi enganada. Era a casa de um traficante: "ouvi uma conversa entre eles que ela iria me vender para aquele traficante." C.22 disse ter se visto perdida nesse instante, sem rumo, sem destino, sem saber o que fazer. Saiu em disparada pelo lugar desconhecido. Ficou por alguns dias no centro da cidade, sem comer nem beber. Sentada sobre um papelão, sem usar drogas, entrou em depressão: "estava segurando minha filha e fazia carinho nela mas ela não estava ali! Ninguem me via ninguém me conhecia." Tudo que ela necessitava naquele momento era um auxílio, mas as pessoas sequer a enxergavam.

Após sete dias nessa situação, saiu suja e mal vestida caminhando pelas ruas. Frente a essa situação, ela relatou que "parou vários carros me oferecendo dinheiro mas eu não aceitei essa realidade." Contudo, a fome e a sede tornaram-se insuportáveis e a obrigaram a aceitar o convite para entrar no carro de um homem bem vestido e "apessoado" que nem de longe ela pensava ser traficante: "ele me levou a uma casa de classe alta num condomínio e ali eu entrei tomei banho comi bastante, ele me convidou para nos fechar algumas pedras de crack..." A seguir, C.22 completa: "perguntei se eu poderia experimentar e ele me deue eu gostei, então ele me colocou nos negócios..." 
RELACult - Revista Latino-Americana de Estudos em Cultura e Sociedade

Revista Latinoamericana de Estudios en Cultura y Sociedad | Revue Latino-américaine d'Études sur la culture et la société |

C.22 não pensou muito e decidiu aceitar a proposta, indo morar numa casa onde assumiu a função de gerente no ponto de venda de drogas. Recebia pelo tráfico não dinheiro, mas sim pedras de crack para o sustento de seu vício. Suas necessidades básicas eram supridas pelo "patrão". A jovem refere-se a essa forma de vida como trabalho.

Com 16 anos o "chefe" a trocou de função: "ele me levou para cavalhada eu fui para roubar e asaltar, conheci o mundo do crime totalmente!" Ao mudar de área de atuação foi recolhida pelas autoridades, que, ao verificarem no sistema, a identificaram como desaparecida há quatro meses e a levaram novamente para sua cidade natal. Em Dom Pedrito C.22 chegou bem debilitada pelo uso excessivo das drogas. Foi hospitalizada com a vida em risco, pesando apenas 28 quilos e com o pulmão esquerdo comprometido: "consegui fazer uma operação pois tanto crack que eu usei acumulo o quero diesel no meu pulmão."

Essa situação estreitou o relacionamento com sua genitora, que já havia se recuperado dos vícios:

depois de todo esse tempo eu vi o amor que minha mãe tinha comigo e a minha família isso vez eu mudar e acreditar que poderia ter uma chance de viver novamente eu quero dizer que é muito difícil sair dessa vida pois quem passa por isso, sabe que e difícil e eu sem motivos para viver me joguei na droga (C.22).

C.22 destacou que a religiosidade foi seu refúgio e fortaleza para a libertação. Entretanto, aos 18 anos sofreu uma recaída. Voltou a traficar, pois "o dinheiro é 'rapido' é 'fácil' e que resolveu os meus problemas então ñ parei mais..." Já adulta, os rigores da lei vieram ao seu encontro:

Baterão na Porta e eu abri pensando que era algum passageiro não era a "Policia" ali mesmo na Porta do Banheiro eles pegarão... fui presa com 19 (dezenove) anos eu estava me perguntando pra mim mesma porque, porque eu tinha feito aquilo oarrependimento, tristeza não só por mim mas por minha família que pensava que eu estava bem (C.22).

Ela diz ter contado com o apoio incondicional de sua mãe, que na primeira visita lhe disse: "minha filha vc é tudo pra mim jamais vou te abandonar, assim como tive do teu lado o tempo todo vou estar contigo sempre. Eu te amo."

Com sete meses de reclusão recebeu o alvará de liberdade provisória e aproveitou para refazer sua vida, constituir família, casar e ter um filho. Fez cursos e se tornou evangélica. Estava gozando de felicidade quando o juiz determinou sua condenação. Diante disso, precisou voltar para a cadeia, como ela mesma relata:

eu estava amamentando e mesmo assim fui recolhida... eu aprendi uma coisa nessas "2 prisões" que eu tive pelo mesmo crime eu não posso e não Devo escrever algo que relate que acontece dentro de uma casa prisional... pois quem sofrerá será nos que estamos atraz da porta pois eu estive na rua e aqui em qualquer presídio você vai sofrer precoiceito muito mais preconceito aqui do que na rua (C.22). 
RELACult - Revista Latino-Americana de Estudos em Cultura e Sociedade

Revista Latinoamericana de Estudios en Cultura y Sociedad | Revue Latino-américaine d'Études sur la culture et la société |

C.22 foi condenada a quatro anos e dois meses de reclusão. O marido não a abandonou e, juntamente com sua mãe, é o responsável pelo cuidado de seu filho. Para ocupar seu tempo na prisão faz artesanato e, com isso, consegue auxiliar a família nas despesas.

\title{
E.36 - um dia eu peguei as miha roupas e fugi eles nei virão e nei derão bola não me
}

\section{procurarão fui mora na rua}

E.36 diz pertencer a uma família trabalhadora e honesta. Sempre moraram num bairro muito pobre, porém nunca lhes faltou alimento na mesa. A educação era rígida e sua mãe tentava conduzi-la pelo caminho considerado correto. Contudo, aos 14 anos de idade E.36 fugiu de sua residência para escapar da violência dupla a qual era submetida: agressões físicas que sofria do seu pai e, ao ser molestada pelos tios, viu-se sem saída, pois

\begin{abstract}
naquela época a palavra da criansa não valia nada um dia eu peguei as minha roupas e Fuji eles Nei vião e Nei derão bola não e procuraram fiu mora na rua dormia na praça .... um dia achei uma amiga que também tinha fugido de casa daí eu não me sentia tão sozinha, nos entrava nos mercado e pegava coisa pra comer um dia pegaram nos com chocolati o bolacha e o dono do mecado pego e escrou nos 2 e dese se nos não mantesse relação com ele ia chamar a policia, a A. se meteu na frente e disse que ficava com ele porque eu era virgem.ai não adiantou ele mandou o segurança agarrar a A. e ficou comigo e o outro com ela, dpois nos largara.. chorei muito achei que ia morrer... Daquele dia em diante eu tinha certeza que jamais eu poderia voutar pra casa.
\end{abstract}

Após esse episódio - algo horrendo e uma das maiores violências a que uma mulher pode ser submetida -, E.36 decidiu continuar residindo nas ruas da cidade. Nesse ambiente em que vivia conheceu um rapaz, com quem teve um relacionamento e engravidou. A família do então namorado, ao ter conhecimento do fato, a levou para casa, deu abrigo e assistência, amenizando o sofrimento: "eu tava felis tilha saído da rua não pasava mais fome."

Essa situação durou somente até a chegada do bebê. A partir dessa realidade tudo começou a mudar novamente, e sua vida voltou a ser igual ou pior que a que vivia no passado. "Quando o M. naseu tudo mudou o milha vida virou um iferno eles conezaro me naltrata" e queriam ficar com seu filho. O companheiro passou a agredi-la fisicamente todos os dias. Em sua memória, ela guarda a fatídica véspera de natal do ano de 1991: “eu pasei o natal no ospil na sala de sirujia o meu marido pai do M. quebrou todos os meus denti da frenti com na bara de fero."

Como ainda era menor de idade, o Conselho Tutelar, órgão responsável pela fiscalização dos direitos da criança e do adolescente, tomou providências e acionou sua família. Entretanto, sua mãe não a aceitou de volta por causa do seu pai. Quando deu alta foi pegar seu filho na residência da sogra. E.36 acabou fugindo com o bebê sem rumo. Conseguiu 
RELACult - Revista Latino-Americana de Estudos em Cultura e Sociedade

Revista Latinoamericana de Estudios en Cultura y Sociedad | Revue Latino-américaine d'Études sur la culture et la société |

abrigo na casa de uma senhora que sempre a ajudava. Refere-se de forma carinhosa à ela: " $a$ dona $S$. me ajudou a cria o M. com a ajuda de outras pessoas que davam leite e fraldas." E segue: "pur esse fiho eu fis tudo na milha vida aprendi a lutar eu não tilha como sustenta a casa ai eu resolvi veder o meu corpo" (E.36).

O tempo passou e ela teve mais cinco filhos. Conheceu o atual marido, envolveu-se com drogas, foi presa junto com o filho primogênito. Sente-se culpada por isso e também por não estar presente na vida dos outros quatro menores. Ao adquirir sua liberdade voltou a traficar: "tinha uma divida muito grande e eles ameaçaram meu filho", o qual ainda estava cumprindo sentença.

Em seus escritos ressalta nunca ter se envolvido com esse tipo de coisa, afirmando que só o fez depois que casou, como salientado no trecho a seguir: "ele tem a maior culpa por eu e meu filho vir para dentro da codeia [...] toda família dele é envolvida com isso a mãe teve presa e o pai talle por trafico a Milla familha so eu que esvergolhei" (E.36).

Atualmente, E.36 cumpre o total de 11 anos de reclusão. É ligada à faxina do alojamento para ganhar remição e ocupar seu tempo. Seu maior desafio no cárcere é relacionar-se: "não uso droga na fumo sigaro e ai fica dificil dese relasiona." E.36 nutre e anseia por liberdade, como diz: "tenho um desespero para ir embora, as pessoas aqui são tão ruins..."

Suas perspectivas futuras se voltam para o objetivo de poder dedicar-se a um serviço lícito e refazer sua vida revestida de dignidade - qualidade que tanto elogia ao comentar sobre seu seio familiar. "Vou poder sair na rua sem ter que me cuidar dapoliça porque não devo mais nada.... vou fazer de tudo para me perdoarem", conclui.

\section{As condições de produções de vidas evidenciadas a partir das narrativas}

Pensar a partir de múltiplas narrativas de vida não é algo descomplicado, pois essas vidas possuem histórias que as construíram como seres pertencentes a uma determinada sociedade. E esta pode e geralmente intervém diretamente no seu presente, colaborando, igualmente, para a construção do seu futuro. A esse respeito, Luke (2000) destaca que não existe um desprendimento da história do ser humano na construção de sua vida, pois esta se encontra diretamente ligada à formação das pessoas e do seu convívio com a sociedade. No caso das vidas referidas neste artigo, ambas pertencem à classe empobrecida da população. $\mathrm{O}$ cercamento de familiares e conhecidos com ligação ao mundo do crime também é constante, o que não lhes proporcionou muitas outras oportunidades de escolha, já que estariam, em alguns casos, talvez, acostumadas a uma vida de submissão. Aliado a isso, a baixa escolaridade e os 
RELACult - Revista Latino-Americana de Estudos em Cultura e Sociedade

Revista Latinoamericana de Estudios en Cultura y Sociedad | Revue Latino-américaine d'Études sur la culture et la société |

vínculos empregatícios de mão de obra de baixa remuneração configuram, a nosso ver, a vulnerabilidade social a que foram expostas.

Não que neste cenário as mulheres figurem somente como vítimas da sociedade e que a pobreza tenha sido o responsável exclusivo pelos desvios de conduta. Porém, temos de considerar que um conjunto de situações convergiu para a inserção dessas mulheres na vida criminosa. Não é nosso intuito, de forma alguma, fazer juízo de valor sobre as narrativas às quais tivemos acesso. Contudo, parece necessário considerar que, talvez, tenham sido encaminhadas por um conjunto de fatores ao "mundo-crime", como os seguintes: desestruturação familiar, desigualdade social, baixa escolaridade, violência às crianças e mulheres. Além disso, o fato de necessitarem, por diversas vezes, arcar com as responsabilidades da família (com muitas ficando desassistidas ao engravidarem, por exemplo), ou simplesmente por considerarem, em algumas oportunidades, o delito cometido como um "trabalho", não o diferenciando dos demais existentes no mercado - ainda que pusessem em risco seus direitos de liberdade -, também pode ser visto como mais um dos fatores recém salientados.

Cabe salientar, nesse sentido, o quanto as mulheres aqui visibilizadas parecem ter sentido os efeitos da não responsabilização dos homens pelos crimes cometidos contra elas. Os abusos, as torturas e a violência simbólica e física cometidos não foram, a partir das escritas realizadas, punidos. Cremos que isso demonstra o quanto as mulheres aprisionadas estão nessa situação em grande parte devido à relação desigual entre os gêneros. Como Scott (1995, p. 21) salienta, o gênero "é um elemento constitutivo de relações sociais baseado nas diferenças percebidas entre os sexos." Assim, as relações de poder e os empoderamentos e desempoderamentos aliam-se às condições constitutivas dessas mulheres e às suas possibilidades de vida.

As mulheres aprisionadas compõem a faixa etária de 22 a 36 anos de idade, possuem filhos e são chefes de família. Assumem, assim, uma função historicamente construída para ser exercida pelo homem, e que, hoje em dia, devido a um conjunto de fatores - incluindo as novas configurações sociais das famílias, em que alguns papéis se inverteram ou até mesmo inexistem -, ostentam esse lugar.

Diante desse contexto, questionamos: a prisão seria capaz de transformá-las? No atual momento, vemos o quanto as condições das prisões dificultam esse tipo de modificação, uma vez que para que isso venha a se tornar possível é necessário refletir a respeito do surgimento do cárcere e pensar que já houve algumas alterações. A prisão surgiu antes da penalidade imposta ao infrator, submetendo-o a degradantes situações de violência na tentativa de 
RELACult - Revista Latino-Americana de Estudos em Cultura e Sociedade

Revista Latinoamericana de Estudios en Cultura y Sociedad | Revue Latino-américaine d'Études sur la culture et la société |

“domar" o ser humano, levando-o a situações subumanas de extremo sofrimento. O indivíduo era tratado como coisa, objeto manipulável, sob a responsabilidade das autoridades religiosas e burguesas da época. Foucault (2013, p. 217) afirma que

\begin{abstract}
A prisão, peça essencial no conjunto das punições, marca certamente um momento importante na história da justiça penal: seu acesso a "humanidade". Mas também um momento importante na história desses mecanismos disciplinares que o novo poder de classe estava desenvolvendo: o momento em que aqueles colonizavam a instituição judiciária.
\end{abstract}

$\mathrm{Na}$ nova constituição do sistema penitenciário, a prisão passou a ter um novo significado para a formação dos seres humanos. O sacrifício físico em forma de punição já praticamente inexiste, pois o(a) apenado(a) atual, ainda que se submeta a deveres impostos pelo sistema prisional, encontra inúmeras flexibilidades em seus cotidianos, contrastando com as intensas rotinas a que eram submetidos os sentenciados do século XVIII e princípio do XIX, tendo a disciplina como principal "arma" para ocupá-los durante a maior parte possível do seu tempo.

Há muitos questionamentos que, por muito tempo, ainda irão continuar em pauta quanto à eficácia da ressocialização oferecida pela prisão. Porém, ainda, não foram apresentadas soluções plausíveis e possíveis de pôr em prática, por inúmeros motivos, tais como:

a) Os recursos financeiros do poder público parecem ser mal utilizados (e/ou insuficientes) para atender à demanda existente, que inclui as necessidades básicas dos indivíduos, como acesso à alimentação, materiais de higiene e estruturas físicas das prisões, entre outros. Acerca disso, C.22 chega a salientar: "eu cheguei e fiquei apavorada erão 42 mulheres 39 camas e eu e mais algumas dormião no chão, muito rato, Barata andavão ao meu lado."

b) $\mathrm{O}$ crescimento da criminalidade tem um reflexo direto no interior das prisões. Isso causa, na maioria das vezes, senão sempre, superlotação. Ou, no caso das mulheres adaptadas em espaços destinados aos homens, um certo "improviso", o que inviabiliza os direitos dessas mulheres, como o direito de conviver com seus filhos no primeiro ano de vida, conforme amparo legal.

c) O fato de que qualquer atividade desenvolvida no interior de uma instituição de prisão poderá sofrer interferência de postergação por razões de segurança e preservação da ordem, necessárias nesse ambiente.

Muitos dos agentes não são compreendidos por essa atitude (referimo-nos ao item c). Porém, quando se conhece uma prisão e sua rotina, percebe-se que os indivíduos que ali se 
RELACult - Revista Latino-Americana de Estudos em Cultura e Sociedade

Revista Latinoamericana de Estudios en Cultura y Sociedad | Revue Latino-américaine d'Études sur la culture et la société |

encontram, por estarem reunidos em grupos, em alguns momentos alteram os ânimos e, com isso, a organização para o controle prisional também se altera. Ao mesmo tempo, é preciso destacar que vivemos em um país onde a desigualdade é uma marca profunda e onde o enfrentamento a outras formas de solução da violência tem sido negligenciado.

Acerca disso, cabe destacar que a ausência de ocupação aos detentos faz com que a maioria permaneça 24 horas sem fazer praticamente nada de aproveitável para preencher o tempo com qualidade, o que às vezes é uma condição para que aconteçam desentendimentos e até agressões, conforme citado na narrativa de E.36: "fauta um curso pras presa fazer algum tipo de atividade aque não tem nada pra fazer e poucas as oputinidade de trabalho [...] un dia cuaze fui linclada [...] eu tilhanedo de dorni La elas ameçavao eu e as outras babalhadora."

Parece que as autoridades apenas pensam em extrair o dito "problema" da sociedade e o acumular em depósitos de oficinas do não saber, aliás, da qualificação para continuidade no crime. Que mudança irá acarretar este ambiente no ser aprisionado? Foucault (2013, p. 225) explica que "não é, portanto, um respeito exterior pela lei ou apenas o receio da punição que vai agir sobre o detento, mas o próprio trabalho de sua consciência." Como exercitar a consciência do(a) detento(a) sem considerar vital a educação, as atividades culturais e educativas, os cursos e os acessos a materiais culturais diversos e a possibilidades efetivas de trabalho e geração de renda, entre outros?

As narrativas das detentas também trouxeram à tona as deficiências da ausência da escolarização formal. Contudo, ainda assim, não comprometeram a comunicação delas com o leitor. Mesmo com dificuldades na escrita, foi possível compreendê-las. As faltas de oportunidades geradas ou não oportunizadas, talvez, tenham viabilizado suas condições atuais de vida. Assim, acreditamos que "os textos são vistos como ações sociais, instâncias significativas e coerentes do uso falado e escrito da linguagem. Sua forma e seu formato, contudo, não são causais ou arbitrários", sendo que seus "tipos ou 'gêneros' específicos de textos servem a usos e funções sociais convencionais" (LUKE, 2000, p. 103).

Parece que a não presença da educação formal, tão necessária e enriquecedora para a prática da cidadania, está associada, ainda, a uma falta de conhecimentos culturais e de oportunidades melhores de vida para estas mulheres. Em relação a isso, recordamos da teoria da desigualdade de gênero, a qual refere

que, por mais que o movimento feminista tenha alcançado importantes êxitos, a mulher permanece em uma situação de desigualdade social e econômica e, sendo chefe de família, a mulher, que muitas vezes se encontra renegada a uma situação de 
RELACult - Revista Latino-Americana de Estudos em Cultura e Sociedade

Revista Latinoamericana de Estudios en Cultura y Sociedad | Revue Latino-américaine d'Études sur la culture et la société |

pobreza, recorre ao crime para garantir a própria sobrevivência e de seus familiares. (HELPES, 2013, p. 167)

A ilicitude, em sua maioria, deveu-se à necessidade de arcar com despesas básicas dos filhos, conforme verificado no trecho a seguir, de E.36:

É pur esse fiho eu fis tudo na milha vida aprendi a lutar eu não tinha como sustenta a casa... [...] Eu tive que trafica de novo porque tilha uma divida muito grande de droga e eles dizerão pro mim que se eu não pagasse o meu filho ia soffrer as consecuencia aqui na cadeia.

Aliado a isso, há o fato de que as mulheres são levadas ao tráfico pelos homens, seus companheiros, na maior parte das vezes. A relação de dependência tanto emocional quanto econômica parece não criar frestas no interior dessas vidas. Como uma condição de produção, a relação de gênero aí estabelecida impõe um determinado lugar social a essas mulheres: a de seguirem os passos de seus companheiros.

As condições múltiplas de produção das vidas das mulheres aprisionadas em Bagé, Rio Grande do Sul, chamam a atenção. Há, assim, muitos entrelaçamentos entre as histórias de vida. Talvez isso seja o anúncio de que essas vidas encarceradas necessitam, também, de escuta, de voz, ao contrário de um julgamento sem a análise ética das suas trajetórias e potencialidades. Recriar e reelaborar os seus trajetos, as suas vidas, afinal, deveria ser uma condição na instituição em que estão, atualmente, inseridas.

\section{Considerações finais}

As vidas pré-cárcere das mulheres aprisionadas são pouco conhecidas. Por isso procuramos, neste artigo, escutar as histórias contadas por elas, almejando que estas mesmas mulheres tenham as suas vozes ouvidas, contribuindo para que a sociedade conheça um pouco mais do que é tão ocultado pelas marcas das relações desiguais de gênero e também pelas relações desiguais entre as classes sociais.

Foucault (2013) afirma que a sociedade não está preparada para suprir as necessidades básicas dos seres humanos porque ela finaliza as possibilidades, aspirações ou exigências que surgirão em seguida ao crime. Nesse sentido, Montero (2008, p. 30) ressalta que "há uma história que não está na história e que só se pode resgatar apurando o ouvido e escutando os sussurros das mulheres." Almejamos apurar a escuta e a atenção ética a cada uma dessas mulheres que nos diziam:

Meu nome é C. [...] um pouco d Atenção de a sua Atenção por um Grito de Socorro que não é ouvido (C.22 anos).

Istoria da miha vida [...] (E.36 anos). 
RELACult - Revista Latino-Americana de Estudos em Cultura e Sociedade

Revista Latinoamericana de Estudios en Cultura y Sociedad | Revue Latino-américaine d'Études sur la culture et la société |

Mediante as escritas das apenadas, efetuadas em cadernos individuais, procuramos realizar uma análise dos relatos e fazer com que as leitoras e os leitores percebam que essas mulheres não estão trancafiadas apenas por uma suposta "opção", mas por um conjunto de condições que colaboraram para que isso viesse a acontecer. Afinal, as histórias de que são feitas as nossas vidas não são criadas apenas por nós mesmos, mas no interior de um conjunto de possibilidades e impossibilidades. Nesse sentido, desigualdades de gênero e classe social são fatores relevantes para pensarmos nas muitas vidas que habitam as prisões femininas de nosso país.

Nessa direção, o aumento da massa carcerária feminina é preocupante e permite que muitas famílias permaneçam compondo a classe menos favorecida da população. Quanto a isso, Foucault (2013, p. 254) afirma que "a prisão fabrica indiretamente delinquentes, ao fazer cair na miséria a família do detento." A falta de proteção no interior das suas famílias e a ausência de formação escolar foram observadas no perfil das mulheres. Além do baixo nível de escolaridade, e provavelmente por isso mesmo, ocupavam atividades de baixa remuneração - característica ocasionada, dentre outros fatores, pela ausência do poder público na implantação de políticas que visem qualificar as pessoas.

Pensamos que a educação é o principal meio através do qual se pode transformar essas vidas tanto antes quanto depois da prisão. Isso porque ela permite que os seres humanos se abram para novas experiências, ampliem os seus repertórios e as suas oportunidades de vida, proporcionando modificações de dentro para fora, e não apenas de formas superficiais. Nesse sentido, este artigo já causou impacto positivo na vida das detentas na medida em que as fez refletir e sentirem-se valorizadas. Permitiu que superassem seus desafios, uma vez que, conforme relataram, tinham dificuldades para escrever.

\section{Referências}

ABRAHÃO, M. H. Memória, narrativas e pesquisa autobiográfica. História da Educação, ASPHE/FaF/UFPel, Pelotas, n. 14, p. 79-95, set. 2003.

BRASIL. Presidência da República. Casa Civil. Subchefia para Assuntos Jurídicos. Lei de execução Penal no 7.210, de 11 de julho de 1984. Institui a Lei de Execução Penal. 1984. Disponível em: https://www2.camara.leg.br/legin/fed/lei/1980-1987/lei-7210-11-julho-1984356938-norma-pl.html. Acesso em: 17 abr. 2020.

CHIES, L. A. B.; VARELA, A. B. A Ambiguidade do Trabalho Prisional num Contexto de Encarceramento Feminino: o círculo vicioso da exclusão. In: XIII CONGRESSO

BRASILEIRO DE SOCIOLOGIA. Sociedade Brasileira de Sociologia. 29 de maio a 01 de junho de 2007, UFPE, Recife (PE). GT30: Violência e Sociedade: segurança, controle e 
RELACult - Revista Latino-Americana de Estudos em Cultura e Sociedade

Revista Latinoamericana de Estudios en Cultura y Sociedad | Revue Latino-américaine d'Études sur la culture et la société |

castigo. Anais... Pernambuco, 2007. Disponível em:

http://www.sbsociologia.com.br/portal/index.php?option=com_docman\&task=cat_view\&gid $=160 \&$ Itemid=171. Acesso em: 17 abr. 2020.

FOUCAULT, M. A escrita de si. In: FOUCAULT, M. Ética, sexualidade, política. Trad. Elisa Monteiro e Inês Autran Dourado Barbosa. Rio de Janeiro: Forense Universitária, 2004. p. 144-162.

FOUCAULT, M. Vigiar e punir: História da Violência nas Prisões. Trad. Raquel Ramalhete. Rio de Janeiro: Vozes, 2013.

HELPES, S. S. Mulheres na prisão: Uma reflexão sobre a relação do Estado brasileiro com a criminalidade feminina. Revista Cadernos de Estudos Sociais e Políticos, Rio de Janeiro, v. 2, n. 3, p. 160-185, jan./jul. 2013.

LUKE, A. Análise do discurso numa perspectiva crítica. In: HYPOLITO, Á. M.; GANDIN, L. A. (Org.). Educação em tempos de incertezas. Belo Horizonte, Autêntica, 2000. p. 93-110.

MONTERO, R. Histórias de Mulheres. Trad. Joana Angélica d'Avila Melo. Rio de Janeiro: Agir, 2008.

ONOFRE, E. M. C. O papel da escola na prisão: saberes e experiências de alunos e professores. childhood \& philosophy, Rio de Janeiro, v. 7, n. 14, p. 271-297, jul./dez. 2011.

SCOTT, J. Gênero: uma categoria útil de análise histórica. Educação \& Realidade, Porto Alegre, v. 20, n. 2, p. 71-99, jul./dez. 1995. 


\title{
Entrelazamientos entre historias de vida de mujeres aprisionadas: dar la palabra, aguzar la escucha
}

\begin{abstract}
Resumen
El presente artículo parte de la siguiente pregunta: ¿Cómo mujeres aprisionadas en Bagé cuentan sus historias de vida y, al mismo tiempo, a partir de qué condiciones estas mismas historias se entrelazan? El objetivo principal es dar voz a esas mujeres privadas de libertad para problematizar las condiciones sociales y culturales que se incorporan a las historias de vida de las presas. El camino metodológico partió de autobiografías, cuyas escrituras las efectuaron en cuadernos las propias detenidas y posteriormente leídas y analizadas. Tuviera la intención de darles voz a ellas a través de escrituras individuales, teniendo en vista que la escritura es una de las vías que posibilita la reflexión sobre sus propias vidas. Las marcas de género son algo presente en el transcurso de toda la discusión, una vez que las mujeres parecen sometidas al dominio del "mundo masculino", traducido en las relaciones de violencia establecidas por parte de los hombres, por el abandono efectivo, financiero y, también, debido al hecho de las mujeres presas estar, en su mayoría, en la cárcel, debido a ser llevadas a traficar la partir de figuras masculinas.
\end{abstract}

Palabras claves: Cárcel; Género; Mujeres; Historias de vida; Educación.

\section{Entremêlements entre les histoires de vie des femmes emprisonnées: donner la parole et aiguiser l'écoute}

\begin{abstract}
Résumé
Cet article prend comme point de départ la question suivante: Comment les femmes emprisonnées à Bagé racontent-elles leur vie et, en même temps, dans quelles conditions ces histoires s'entremêlent-elles? L'objectif principal est de donner la parole à ces femmes privées de liberté afin que les conditions sociales et culturelles incorporées dans leurs histoires de vie puissent être discutées. La feuille de route méthodologique a commencé par les autobiographies écrites dans des cahiers par les détenues elles-mêmes; ensuite, ces autobiographies ont été lues et analysées. L'intention principale était de leur donner une voix à travers ces écrits individuels, en tenant compte du fait que l'écriture est l'un des moyens qui permet aux personnes de réfléchir à leur propre vie. La recherche aborde des éléments allant des récits de vie avant la prison à une analyse de leur vie, énumérant certains facteurs concernant l'inefficacité et la resocialisation de la prison, ainsi que le manque d'une formation qui peut qualifier ces femmes. Les questions de genre sont présentes tout au long de la discussion, car les femmes semblent soumises à la domination du «monde masculin», ce qui est traduit par des relations de violence établies par les hommes, par l'abandon affectif, par des problèmes financiers et par le fait que les femmes détenues sont incarcérées principalement parce qu'elles ont été amenées à commettre des délits de trafic par des hommes.
\end{abstract}

Mots-clés: Prison; Genre; Femmes; Histoires de vie; Formation.

\section{Intertwining Between Life Stories of Imprisoned Women: Giving a Voice, Sharpening the Listening}

\begin{abstract}
This article takes as a starting point the following question: In what ways do imprisoned women in the city of Bagé tell their life stories, and also under what conditions do these same stories are intertwined? The main goal is to give a voice to these women who have been deprived of liberty so that they may discuss the social and cultural conditions that are incorporated into the life stories of these detainees. The methodological road map


started with autobiographies that were written in notebooks by the detainees themselves; afterwards, these were read and analyzed. The intention was to give them a voice through individual writings, taking into account the fact that writing is one of the ways that allows people to reflect on their own lives. Gender issues are present throughout the discussion, as women seem to be subjected to the domination of the "male world", which is translated into relationships of violence established by men, by affective abandonment, by financial troubles and by the fact that women prisoners are in prison mostly because they are led to trafficking by male figures.

Keywords: Prison; Gender; Women; Life stories; Education. 